\title{
. Virtual Affinity Fingerprints for Target Fishing: A New Application of Drug Profile Matching
}

3 Ágnes Peragovics, ${ }^{\dagger, \S}$ Zoltán Simon ${ }^{\S}, \|$ László Tombor, ${ }^{\perp}$ Balázs Jelinek, ${ }^{\ddagger, \S}$ Péter Hári, ${ }^{\S}, \|$ Pál Czobor, ${ }^{\perp}$ 4 and András Málnási-Csizmadia ${ }^{*},+, \$$

$5{ }^{\dagger}$ Department of Biochemistry, Institute of Biology, Eötvös Loránd University, Pázmány Péter sétány 1/C, H-1117 Budapest, Hungary

$6{ }^{\ddagger}$ Molecular Biophysics Research Group, Hungarian Academy of Sciences - ELTE, Budapest, Hungary

$7{ }^{\S}$ Drugmotif Ltd., Szent Erzsébet krt. 14, H-2112 Veresegyház, Hungary

8 "Printnet Ltd., Petneházy utca 52, H-1139 Budapest, Hungary

${ }_{9}^{\perp}$ Department of Psychiatry and Psychotherapy, Semmelweis University, Balassa utca 6, H-1083 Budapest, Hungary

ABSTRACT: We recently introduced drug profile matching (DPM), a novel virtual affinity fingerprinting bioactivity prediction method. DPM is based on the docking profiles of ca. 1200 FDA-approved small-molecule drugs against a set of nontarget proteins and creates bioactivity predictions based on this pattern. The effectiveness of this approach was previously demonstrated for therapeutic effect prediction of drug molecules. In the current work, we investigated the applicability of DPM for target fishing, i.e. for the prediction of biological targets for compounds. Predictions were made for 77 targets, and their accuracy was measured by receiver operating characteristic (ROC) analysis. Robustness was tested by a rigorous 10-fold cross-validation procedure. This procedure identified

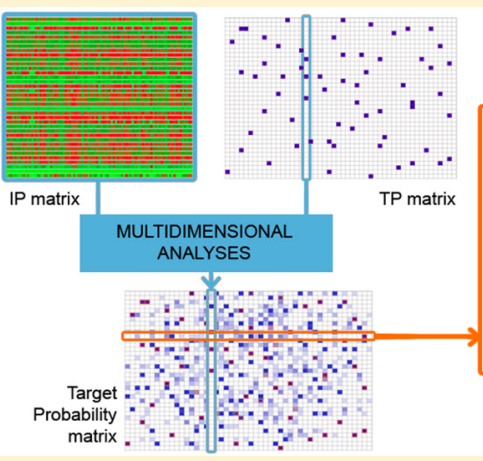
SYSTEMATIC IN SILICO TARGET FISHING targets $(N=45)$ with high reliability based on DPM performance. These 45 categories were used in a subsequent study which aimed at predicting the off-target profiles of currently approved FDA drugs. In this data set, 79\% of the known drug-target interactions were correctly predicted by DPM, and additionally 1074 new drug-target interactions were suggested. We focused our further investigation on the suggested interactions of antipsychotic molecules and confirmed several interactions by a review of the literature.

30 Finding compounds for a given target is a common computa31 tional task in a conventional medicinal chemistry program. However, 32 by means of increasingly available bioactivity data, this 33 approach can be reversed to finding targets for compounds. 34 In silico target fishing ${ }^{1}$ is an emerging field that aims at pre35 dicting biological targets of molecules based on their chemical 36 structure. The rise of this area is in connection with that of 37 polypharmacology, ${ }^{2,3}$ which posits that drugs act on multiple 38 targets in contrast with the traditional one drug-one target 39 paradigm. As a consequence, it is likely to discover new targets 40 even for well-known drugs.

41 Many in silico target prediction tools have been developed, 42 and they were summarized by a recent review. ${ }^{4}$ As it is common 43 for drug development methods, target prediction tools can also 44 be divided into two main groups: ligand-based and structure45 based approaches.

46 Similarity search is often used among the ligand-based methods. 47 The most common question that arises in case of similarity 48 based virtual screening is the description of molecular structure. 49 No universal solution seems to exist for this problem, ${ }^{5}$ as the best representation used to characterize the molecules depends 50 on the studied activity classes. Therefore, it is important to 51 combine several methods for a given task, e.g. by applying data 52 fusion techniques. ${ }^{6}$ An approach that generates off-target profiles 53 of drugs based on their 3D similarity has just been reported, 54 and some of its predictions were proved by a literature survey. ${ }^{7} 55$

Several ligand-based methods apply data mining methods in 56 order to identify unknown drug-target interactions. One of the 57 first initiatives in this field was PASS developed by Poroikov et 58 al. ${ }^{8}$ It can predict the biological activity profile of a compound 59 based on the analysis of structure-activity relationships for 60 more than 250000 biologically active substances. Nigsch et al. 61 implemented the Winnow and Naive Bayesian algorithms for 62 ligand-target prediction and compared their performance on a 63 data set comprising 20 activity classes with 13000 compounds. ${ }^{9} 64$ They generally produced similar performance, however, 65 significant differences were observed for the individual activity 66 classes. The similarity ensemble approach (SEA) uses a minimal 67

Received: September 19, 2012 
68 spanning tree considering ligand chemical similarity in order to 69 clusterize 246 enzymes and receptors. ${ }^{10,11}$ On the basis of the 70 model, target prediction was performed for more than 3000 71 FDA approved drugs, and 23 suggested interactions were 72 confirmed experimentally.

73 Pharmacophore based methods also proved to be successful 74 to predict protein targets. PharmMapper employs pharmaco75 phore models derived from structures complexed with small mole76 cules to identify target candidates of query molecules. ${ }^{12}$ 77 Tamoxifen was selected as a validation example, and it was 78 concluded that the method was successful in predicting its 79 targets.

80 Molecular docking is far the most often used tool among the 81 structure-based methods. While conventionally it is applied to 82 identify potential ligands for a given protein, for target pre83 diction the so-called inverse docking procedure needs to be applied 84 (docking one ligand against multiple targets). INVDOCK ${ }^{13}$ 85 and TarFishDock ${ }^{14}$ are examples of recently presented methods 86 for predicting protein targets for small molecules based on 87 docking against a set of proteins supposedly interacting with 88 the ligand.

89 This concept has some relation to in silico affinity finger90 prints, ${ }^{15-17}$ which are a series of docking scores against a reference 91 panel of proteins that do not include the target protein (one 92 ligand, multiple proteins). However, this approach is not 93 designed to find possible targets among the reference proteins. 94 Instead, these reference proteins are used as a discriminator 95 surface which can differentiate a wide range of compounds. In 96 contrast to the computationally more demanding inverse 97 docking, individual interactions are not considered here, the 98 resulting pattern is characteristic for the studied molecules.

99 Affinity fingerprints were originally based on in vitro 100 measurements; ${ }^{18^{-20}}$ however, the measured values were later 101 replaced by docking scores (virtual binding free energies). In 102 silico affinity fingerprints were successfully applied in virtual 103 screening protocols ${ }^{16,21}$ and focused library design. ${ }^{22}$

104 We recently introduced drug profile matching (DPM), a 105 novel virtual affinity fingerprinting prediction method. DPM is 106 based on the docking profiles of ca.1200 FDA-approved small107 molecule drugs against a panel of nontarget proteins. Individual 108 interactions are not investigated in the method; instead, a 109 docking profile serves as a pattern that is characteristic for a 110 given molecule. Our working hypothesis was that similar 111 patterns indicate similar bioactivity of the respective molecules 112 and this feature can be exploited for bioactivity prediction. 113 Relevant information of the docking profiles was extracted by 114 multidimensional statistical techniques that produced proba115 bilities showing the likelihood of having the investigated 116 property for each molecule. The effectiveness of this approach 117 was already demonstrated for pharmacological effect predic118 tion. $^{23}$ Moreover, we also showed that DPM adds additional 119 predictive power to drug effect prediction as compared to 120 traditional molecular similarity based approaches. ${ }^{24}$ Candidate 121 molecules were tested in vitro for three selected categories, and 122 high hit rates were obtained which further proved the validity of 123 DPM predictions (unpublished results). The system was 124 formerly trained on pharmacological effects (medical indica125 tions) based on the categories listed in the DrugBank database. 126 Groups based on common targets were also included among 127 the studied categories and resulted in high classification 128 accuracy. Therefore, as a continuation of our work, we decided 129 to pursue a study on drug-target interaction data. Our current 130 approach is similar to the original application of affinity fingerprints presented by Kauvar et al. In their pioneer work, 131 the binding potencies of several compounds were measured 132 against a reference panel of proteins and the resulting affinity 133 fingerprints of the compounds were applied to predict their 134 binding properties to other proteins not included in the 135 reference panel. ${ }^{18,19}$ In our approach, we also aim to predict 136 interactions between the studied molecules and possible drug 137 targets that are not represented in the reference protein set 138 used to generate the interaction patterns of the compounds by 139 molecular docking.

In the present study, DPM predictions were made based on 141 77 targets extracted from the DrugBank database that contain 142 at least 10 registered molecules in order to provide sufficient 143 amount of information about the active molecules. It should be 144 noted that there is no overlap between the reference protein set 145 used for creating the interaction patterns and the investigated 146 77 targets. The reference protein set consists of only nontarget 147 proteins. Similar to our previous work, the accuracy of DPM 148 predictions was assessed by receiver operating characteristic 149 (ROC) analysis, while robustness was measured via 10 -fold 150 cross-validation. On the basis of the calculated prediction 151 properties, 45 targets possessing sufficient prediction power 152 were selected for further analysis. Predicted off-target profiles 153 with this reduced target set were examined in order to reveal 154 new drug-target interactions. For many drug molecules, 155 significantly more targets were predicted with high probability 156 than it was originally registered in the database. Predicted off- 157 target profiles were examined for selected molecules, and the 158 validity of several suggested interactions was demonstrated by a 159 review of the literature.

\section{METHODS}

161

Drug Profile Matching Method. DPM was described in 162 detail in our recent publications. ${ }^{23,24}$ The key steps of the 163 method and the analyses used to describe its accuracy and 164 robustness are presented briefly in the following.

165

Creation of the Interaction Pattern Matrix. Here 1177166 FDA approved small-molecule drugs were extracted from 167 DrugBank database and were docked to 135 nontarget proteins 168 from RCSB Protein Data Bank (PDB) (Table S1, Supporting 169 Information). Docking was performed using DOVIS 2.0170 software (DOcking-based VIrtual Screening), ${ }^{25}$ AutoDock4 171 docking engine, ${ }^{26}$ Lamarckian genetic algorithm, and X- 172 SCORE scoring function. ${ }^{27}$ The geometrical center of the 173 original ligand was used as a center of the docking box, box size 174 and grid spacing were set to 22.5 and $0.375 \AA$, respectively. 175 Twenty-five docking runs were performed for each job, and the 176 best docking scores for each drug-protein complex were used 177 to form the interaction pattern (IP) matrix. In this matrix, drugs 178 are organized into rows while proteins are in the columns 179 therefore each row represents the IP of a given drug against the 180 reference protein set.

181

For a more detailed description of IP generation see the 182 Supporting Information.

Creation of the Target Profile Matrix. Target informa- 184 tion on 1177 FDA approved small-molecule drugs was 185 extracted from DrugBank database. For 20 molecules no target 186 information could be obtained; these molecules were excluded 187 from further analysis. The resulting 1157 drugs were assigned 188 to 1163 targets that were reviewed manually. The number of 189 categories was reduced to 995 by merging cohesive target 190 groups (for example, DNA topoisomerase 4 subunit A and 191 subunit B were combined to produce the final DNA 192 
193 topoisomerase 4 category). Figure 1 shows the distribution of 194 the registered drugs for these 995 targets. Remarkably, to 628

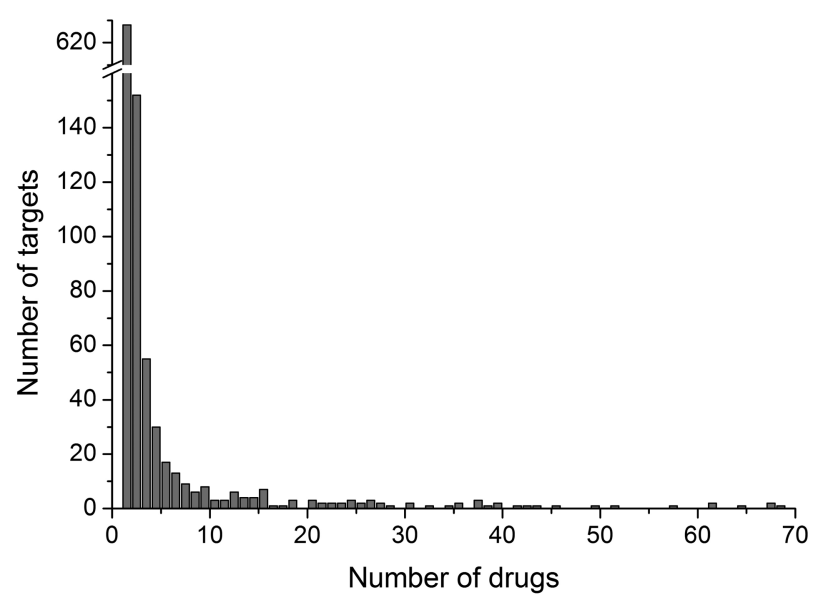

Figure 1. Distribution of the registered drugs for the original 995 targets. Number of targets with a given number of approved drugs is displayed. Note that for more than $60 \%$ of the targets only one molecule is assigned.

195 targets only one drug is assigned in the database, raising dif196 ficulties to exploit this information for prediction with our method. 197 There are only 6 targets having more than 60 assigned drugs: 198 histamine H1 (68 drugs), muscarinic acetylcholine receptor M1 199 (67 drugs), alpha 1A adrenergic receptor (67 drugs), DNA (64 200 drugs) dopamine D2 receptor (61 drugs), and GABA receptor 201 (61 drugs). The mean of the registered drugs to the 995 targets 202 is 3.6, supporting the general view of polypharmacology that 203 drugs act on multiple targets. According to our previous 204 experience gained in therapeutical effect predictions, DPM 205 requires 10 active molecules for sufficient classification. Thus, 206 from the original 995 target groups, only 77 could be kept for 207 the analyses having at least ten registered molecules. This 208 investigated target set is independent of the reference protein 209 set used to generate the interaction patterns. A binary matrix 210 called Target Profile (TP) matrix was created based on these 77 211 groups that displays whether a drug interacts with a given target 212 according to DrugBank. (" 1 " marks the presence of the inter213 action while " 0 " indicates that a given drug-target interaction 214 was not documented). Targets are organized into columns 215 whereas drugs are in the rows of this matrix; therefore, one row 216 represents the DrugBank documented target profile of a given 217 drug. Since many targets were excluded due to the fact that they 218 have less than 10 active molecules, there are several drugs 219 whose target profile is empty. This issue does not raise 220 problems for DPM since the statistical analyses are performed 221 separately for each target (i.e., column by column), as it is 222 described in the following section.

223 Creation of the Target Probability Matrix. Canonical 224 correlation analysis (CCA) was performed between the IP 225 matrix and each target to generate a factor pair having as high 226 correlation as possible via linear combination of the original 227 variables. This factor pair was used as an input for linear 228 discriminant analysis (LDA) that yielded classification functions 229 which were applied to calculate the probability for each drug230 target pair. These probability values were used to create the 231 target probability matrix. Any row of this matrix represents the 232 predicted off-target profile of a given drug. In contrast to the 233 binary target profile matrix, the values in this matrix are continuous, and therefore assignment of a given target to a 234 particular drug also depends on the used probability threshold. 235

An example on a small data set that illustrates the different 236 steps of the DPM method resulting in the final probability 237 values is presented in the Supporting Information.

238

Receiver Operating Characteristic Analysis. Receiver 239 operating characteristic (ROC) analysis was used for assessing 240 the accuracy of the classification functions. To create a ROC 241 curve for each target group, the true positive rate (TPR) was 242 plotted as a function of the false positive rate (FPR) using a 243 sliding cutoff parameter from 0 to 1 for the probabilities. 244 Molecules are reclassified at each cutoff value, labeling 245 compounds as "positive" if they have a greater probability for 246 a given target than the applied cutoff point and "negative" in 247 the opposite case. TPR (also called sensitivity) is the portion of 248 positives classified correctly, while FPR (1-sensitivity) is the 249 rate of negatives which were wrongly classified as positive. To 250 produce a quantitative summary measure of the ROC curve, the 251 area under the curve (AUC) was calculated. Perfect classifica- 252 tion results in an AUC of 1, because in that case there exists a 253 cutoff value above that all positive molecules but no negative 254 molecules are classified as positive and thus the curve runs 255 through the $(0,1)$ point. Therefore, the closer the calculated 256 AUC value is to 1 , the better the classification. A random 257 classification would result in a diagonal ROC curve (AUC of 0.5), 258 representing a method with no ability to distinguish active 259 and inactive molecules. New measures have been introduced 260 recently such as BEDROC that also take into account the 261 shape of the ROC curves, ${ }^{28}$ resulting in higher values for 262 those curves that rise steeply along the $x$ axis, meaning that 263 known actives are indentified at the top of the list. 264 Calculation of the BEDROC metric was performed in our 265 earlier work, ${ }^{23}$ but it did not result in different conclusions 266 than the use of the AUCs. Therefore, we decided to use AUC 267 values in the current work.

10-fold Cross-validation. In order to evaluate the 269 robustness of the results and control for possible overfitting, 270 10 -fold cross-validation was performed. The data was divided 271 into 10 complementary subsets. Each subset was used as a test 272 set for validation while the residual subsets were combined to 273 produce the training set. In each round of the validation, CCA 274 and LDA was performed on the training set and probabilities 275 were predicted for the test set that show the likelihood of 276 interacting with a given target for each test molecule. 277 Accordingly, the classification function was created without 278 considering the test set, ensuring that the test set was 279 completely independent of the training set. Variable selection 280 was not performed in the cross-validation loop as the same set 281 of the predefined 135 nontarget proteins was used in each 282 round of the validation. This process was repeated for each of 283 the 10 subsets, and the probability values for each of the 284 originally registered drugs to a given target were averaged to 285 produce a single measure (mean probability value, MPV) that 286 indicates the robustness of the studied target. This process was 287 repeated 100 times for each target group to eliminate the 288 impact of the distribution of molecules on the results. The 289 outcomes of the 100 runs were combined to create the 290 investigated mean MPVs that describe the robustness of a given 291 target, i.e. to what extent the classification can be generalized on 292 external data. The closer the MPV to 1, the better is the 293 performance of the method on the external data for the studied 294 target group.
295 
296 A validation based on ChEMBL data for a subset of the 297 investigated interactions is presented in the Supporting 298 Information.

299 Target Selectivity Analysis. In order to assess the target 300 selectivity of the studied drugs, the number of predicted targets 301 above a certain probability limit $(>0.8)$ was counted. To ensure 302 nonbiased analysis, from the 77 original targets only the 45 303 highly reliable targets with the best robustness values (mean $304 \mathrm{MPV}>0.5$ ) were used. The predicted interactions of anti305 psychotics was investigated in more detail by a literature survey. 306 Tanimoto Diversity Calculation. Two-dimensional 307 hashed chemical fingerprints, that encode topological proper308 ties of the chemical graph up to six bonds, were generated using 309 ChemAxon's JChem based software for each drug molecule. 310 The process resulted in a 4096-bit-long binary fingerprint for 311 each drug. Then, ChemAxon Similarity plugin was used to 312 calculate the Tanimoto similarity for each possible drug pair on 313 the basis of these fingerprints:

$$
\operatorname{SIM}(\mathrm{A}, \mathrm{B})=\frac{c}{a+b+c}
$$

314 where $a$ is the number of bits on in molecule $\mathrm{A}, b$ is the number 315 of bits on in molecule $\mathrm{B}$, and $c$ is the number of bits in common 316 in both structures.

317 Comparing identical molecules results in a similarity value of 318 1, while the calculated similarity is 0 when two molecules have 319 no bits in common. The average Tanimoto similarity (referred 320 to as Tanimoto diversity) was calculated for each of the studied 321 targets to quantify the structural distribution of the registered 322 molecules. Considerable structural similarity exists among the 323 ligands of a given target if the Tanimoto diversity exceeds 0.6. 324 If this value is less than 0.4 , a target group is considered struc325 turally heterogeneous.

326 The Statistical Analysis System for Windows (version 9.2; 327 SAS Institute, Cary, NC) was used for the implementation of 328 all analyses.

\section{RESULTS AND DISCUSSION}

330 Figure 2 displays a graphical summary of the drug profile 331 matching method applied for target fishing. Virtual binding 332 affinity values obtained by docking 1157 FDA-approved drugs 333 to 135 nontarget proteins were entered into a matrix, where 334 each row displays the interaction pattern (IP) of a given drug 335 against this protein set. On the basis of the target information 336 extracted from DrugBank for the studied molecules, a binary 337 matrix called target profile (TP) matrix was created which 338 shows whether a given drug-target interaction is documented in 339 the DrugBank database. A two-step multidimensional method 340 (CCA and LDA) was applied on these matrices to yield 341 probabilities for each drug that indicates the likelihood of 342 interacting with a given target. These probabilities were entered 343 into the target probability matrix where each row shows the 344 predicted off-target profile of a given drug. It should be noted 345 that these values do not yield any information about the 346 strength of the suggested drug-target interaction that requires 347 in vitro measurements in order to be determined.

348 Receiver Operating Characteristic Analysis. Overall 349 classification accuracy of DPM was measured by receiver 350 operating characteristic (ROC) analysis which is based on the 351 list of drugs sorted by descending probability for a selected 352 target (a column in the target probability matrix). Table 1 lists 353 the obtained AUC values while Figure 3 shows their distribu354 tion for the 77 studied target groups. All AUC values were

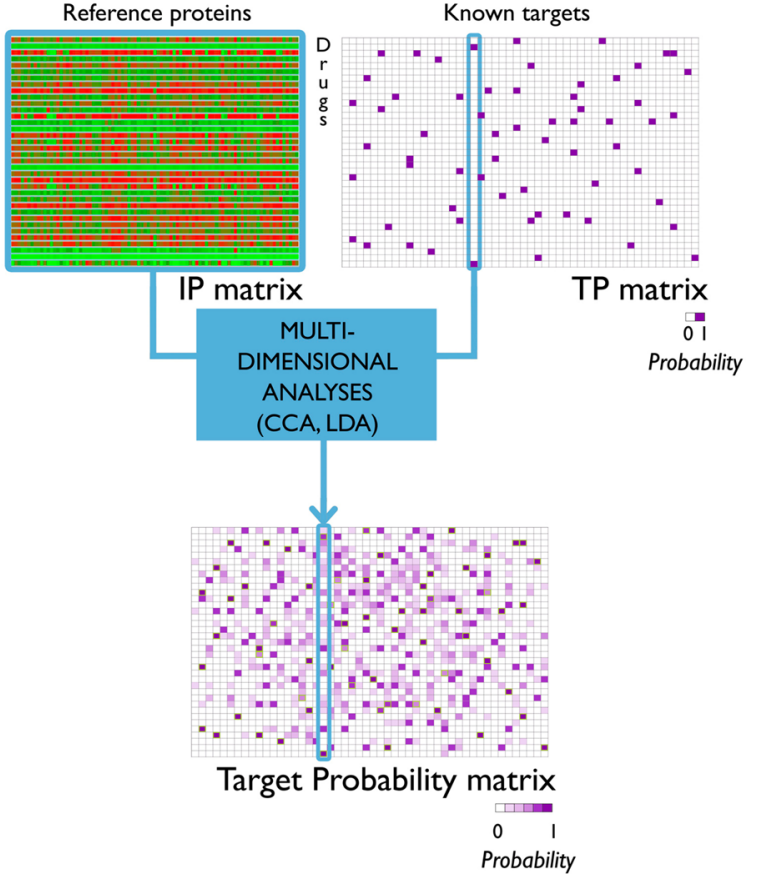

Figure 2. Graphical summary of the drug profile matching method applied for target fishing. The interaction pattern (IP) matrix contains the calculated binding free energies for the studied 1157 drugs on the reference panel of 135 nontarget proteins. The target profile (TP) matrix shows the known drug-target interactions in a binary coded form (purple cells mark the presence of the interaction while white cells indicate that a given drug-target interaction was not documented in DrugBank). These matrices were subjected to a two-step multidimensional analysis (canonical correlation analysis, CCA, and linear discriminant analysis, LDA) that resulted in the target probability matrix that consists of the predicted probabilities for each drug-target pair.

above 0.92, meaning that excellent classification was obtained 355 by DPM for target prediction. Perfect classification (i.e., AUC 356 of 1) occurred for three categories, registered ligands of both 357 target groups share high degree of structural similarity (fluoro- 358 quinolone antibiotics targeting DNA topoisomerase 4, sulphanil- 359 amides targeting dihydropteroate synthase, and steroid 360 molecules targeting progesterone receptor; Tanimoto diver- 361 sities of $0.766,0.505$, and 0.545 , respectively; see Table 1 for 362 the complete list of the Tanimoto diversities). Structural similarity 363 of registered ligands can be observed for several other target 364 groups among the best categories (glucocorticoid receptor, 365 peptidoglycan synthetase ftsl, penicillin binding protein 2A). 366 However, target groups comprising of structurally diverse 367 compounds also obtained high AUC values (0.998 for 368 cholinesterase and 0.997 for monoamine oxidase A; Tanimoto 369 diversities of their registered ligands are 0.241 and $0.380,370$ respectively). This is in an agreement with our previous finding 371 that DPM can effectively handle classes comprising of 372 structurally diverse molecules. ${ }^{24}$ These are the cases where 373 DPM has additional prediction power compared to traditional 374 similarity based approaches. The worst but still excellent AUC 375 of 0.922 was obtained for neuronal acetylcholine receptor, 376 target of mainly barbiturate molecules (Tanimoto diversity of 377 $0.358)$.

Cross-validation. To check the validity of the obtained 379 classifications, an independent 10 -fold cross-validation was 380 performed. The MPVs of the 100 runs were averaged to 381 
Table 1. Prediction and Validation Properties of the Studied 77 Target Groups ${ }^{a}$

\begin{tabular}{|c|c|c|c|c|c|}
\hline \multirow[b]{2}{*}{ target } & \multirow[b]{2}{*}{$n$} & \multirow[b]{2}{*}{ AUC } & \multicolumn{2}{|c|}{$\begin{array}{l}\text { 10-fold cross- } \\
\text { validation }\end{array}$} & \multirow{2}{*}{$\begin{array}{l}\text { Tanimoto } \\
\text { diversity }\end{array}$} \\
\hline & & & mean & std & \\
\hline acetylcholinesterase & 18 & 0.991 & 0.322 & 0.047 & 0.271 \\
\hline alpha- $1 \mathrm{~A}$ adrenergic receptor & 67 & 0.951 & 0.622 & 0.016 & 0.382 \\
\hline alpha-1B adrenergic receptor & 39 & 0.946 & 0.467 & 0.021 & 0.399 \\
\hline alpha-1D adrenergic receptor & 23 & 0.965 & 0.321 & 0.038 & 0.398 \\
\hline alpha- $2 \mathrm{~A}$ adrenergic receptor & 51 & 0.945 & 0.492 & 0.020 & 0.378 \\
\hline alpha-2B adrenergic receptor & 30 & 0.976 & 0.436 & 0.024 & 0.394 \\
\hline alpha-2C adrenergic receptor & 26 & 0.982 & 0.386 & 0.027 & 0.395 \\
\hline androgen receptor & 14 & 0.993 & 0.656 & 0.048 & 0.429 \\
\hline $\begin{array}{l}\text { angiotensin-converting } \\
\text { enzyme }\end{array}$ & 13 & 0.997 & 0.503 & 0.037 & 0.618 \\
\hline arachidonate 5-lipoxygenase & 13 & 0.988 & 0.112 & 0.038 & 0.336 \\
\hline $\begin{array}{l}\text { ATP-binding cassette } \\
\text { transporter subfamily C } \\
\text { member } 8\end{array}$ & 13 & 0.997 & 0.494 & 0.068 & 0.495 \\
\hline Beta-1 adrenergic receptor & 37 & 0.982 & 0.722 & 0.020 & 0.508 \\
\hline Beta-2 adrenergic receptor & 41 & 0.987 & 0.734 & 0.017 & 0.515 \\
\hline calmodulin & 15 & 0.982 & 0.227 & 0.036 & 0.409 \\
\hline $\begin{array}{l}\text { cAMP-specific } 3^{\prime}, 5^{\prime} \text {-cyclic } \\
\text { phosphodiesterase } 4\end{array}$ & 12 & 0.989 & 0.353 & 0.039 & 0.456 \\
\hline carbonic anhydrase 1 & 20 & 0.993 & 0.459 & 0.019 & 0.417 \\
\hline carbonic anhydrase 2 & 20 & 0.997 & 0.512 & 0.021 & 0.429 \\
\hline carbonic anhydrase 4 & 16 & 0.996 & 0.578 & 0.027 & 0.448 \\
\hline cholinesterase & 12 & 0.998 & 0.227 & 0.044 & 0.241 \\
\hline cytochrome P450 51 & 12 & 0.999 & 0.317 & 0.053 & 0.569 \\
\hline $\mathrm{D}(1)$ dopamine receptor & 43 & 0.958 & 0.668 & 0.013 & 0.423 \\
\hline $\mathrm{D}(2)$ dopamine receptor & 61 & 0.965 & 0.656 & 0.011 & 0.410 \\
\hline $\mathrm{D}(3)$ dopamine receptor & 25 & 0.992 & 0.422 & 0.030 & 0.420 \\
\hline $\mathrm{D}(4)$ dopamine receptor & 21 & 0.988 & 0.357 & 0.034 & 0.409 \\
\hline delta-type opioid receptor & 22 & 0.974 & 0.587 & 0.017 & 0.564 \\
\hline dihydropteroate synthase & 10 & 1.000 & 0.800 & 0.042 & 0.505 \\
\hline DNA & 64 & 0.965 & 0.575 & 0.016 & 0.330 \\
\hline DNA gyrase & 15 & 0.996 & 0.737 & 0.024 & 0.705 \\
\hline DNA topoisomerase 2 & 21 & 0.994 & 0.691 & 0.034 & 0.512 \\
\hline DNA topoisomerase 4 & 13 & 1.000 & 0.820 & 0.028 & 0.766 \\
\hline estrogen receptor & 27 & 0.972 & 0.694 & 0.031 & 0.418 \\
\hline $\begin{array}{l}\text { gamma-aminobutyric acid } \\
\text { receptor }\end{array}$ & 61 & 0.985 & 0.674 & 0.013 & 0.337 \\
\hline glucocorticoid receptor & 37 & 0.999 & 0.901 & 0.010 & 0.636 \\
\hline glutamate receptor NOS & 34 & 0.957 & 0.563 & 0.013 & 0.333 \\
\hline histamine $\mathrm{H} 1$ receptor & 68 & 0.957 & 0.695 & 0.010 & 0.383 \\
\hline kappa-type opioid receptor & 23 & 0.977 & 0.488 & 0.017 & 0.502 \\
\hline monoamine oxidase A & 10 & 0.997 & 0.488 & 0.061 & 0.380 \\
\hline Mu-type opioid receptor & 28 & 0.982 & 0.553 & 0.013 & 0.552 \\
\hline $\begin{array}{l}\text { muscarinic acetylcholine } \\
\text { receptor M1 }\end{array}$ & 67 & 0.953 & 0.656 & 0.009 & 0.396 \\
\hline $\begin{array}{l}\text { muscarinic acetylcholine } \\
\text { receptor M2 }\end{array}$ & 49 & 0.944 & 0.536 & 0.015 & 0.373 \\
\hline $\begin{array}{l}\text { muscarinic acetylcholine } \\
\text { receptor M3 }\end{array}$ & 45 & 0.954 & 0.566 & 0.016 & 0.403 \\
\hline $\begin{array}{l}\text { muscarinic acetylcholine } \\
\text { receptor M4 }\end{array}$ & 30 & 0.961 & 0.557 & 0.020 & 0.396 \\
\hline muscarinic acetylcholine & 26 & 0.965 & 0.535 & 0.018 & 0.391 \\
\hline
\end{tabular}

\begin{tabular}{|c|c|c|c|c|c|}
\hline \multirow[b]{2}{*}{ target } & \multirow[b]{2}{*}{$n$} & \multirow[b]{2}{*}{ AUC } & \multicolumn{2}{|c|}{$\begin{array}{l}\text { 10-fold cross- } \\
\text { validation }\end{array}$} & \multirow{2}{*}{$\begin{array}{l}\text { Tanimoto } \\
\text { diversity }\end{array}$} \\
\hline & & & mean & std & \\
\hline $\begin{array}{l}\text { neuronal acetylcholine } \\
\text { receptor }\end{array}$ & 35 & 0.922 & 0.519 & 0.014 & 0.358 \\
\hline penicillin-binding protein $1 \mathrm{~A}$ & 24 & 0.991 & 0.589 & 0.034 & 0.698 \\
\hline penicillin-binding protein $1 \mathrm{~b}$ & 22 & 0.990 & 0.597 & 0.041 & 0.699 \\
\hline penicillin-binding protein 2 & 12 & 0.997 & 0.406 & 0.065 & 0.751 \\
\hline penicillin-binding protein $2 \mathrm{~B}$ & 15 & 0.995 & 0.452 & 0.053 & 0.720 \\
\hline penicillin-binding protein $2 \mathrm{a}$ & 15 & 0.998 & 0.610 & 0.045 & 0.708 \\
\hline penicillin-binding protein 3 & 24 & 0.994 & 0.670 & 0.037 & 0.681 \\
\hline $\begin{array}{l}\text { penicillin-binding proteins } \\
1 \mathrm{~A} / 1 \mathrm{~B}\end{array}$ & 18 & 0.997 & 0.724 & 0.055 & 0.690 \\
\hline peptidoglycan synthetase ftsI & 12 & 0.999 & 0.528 & 0.060 & 0.793 \\
\hline $\begin{array}{l}\text { peroxisome proliferator- } \\
\text { activated receptor }\end{array}$ & 18 & 0.987 & 0.413 & 0.034 & 0.399 \\
\hline $\begin{array}{l}\text { potassium voltage-gated } \\
\text { channel subfamily } \mathrm{H} \\
\text { member } 2\end{array}$ & 20 & 0.976 & 0.381 & 0.038 & 0.431 \\
\hline progesterone receptor & 14 & 1.000 & 0.717 & 0.039 & 0.545 \\
\hline $\begin{array}{l}\text { prostaglandin } \mathrm{G} / \mathrm{H} \text { synthase } \\
\quad 1\end{array}$ & 38 & 0.970 & 0.612 & 0.020 & 0.345 \\
\hline $\begin{array}{l}\text { prostaglandin } \mathrm{G} / \mathrm{H} \text { synthase } \\
2\end{array}$ & 42 & 0.976 & 0.649 & 0.020 & 0.356 \\
\hline reverse transcriptase & 10 & 0.996 & 0.392 & 0.086 & 0.530 \\
\hline $\begin{array}{l}\text { sodium channel protein type } \\
10\end{array}$ & 14 & 0.991 & 0.463 & 0.041 & 0.505 \\
\hline $\begin{array}{l}\text { sodium channel protein type } \\
5\end{array}$ & 27 & 0.959 & 0.345 & 0.025 & 0.396 \\
\hline $\begin{array}{l}\text { sodium-dependent } \\
\text { dopamine transporter }\end{array}$ & 26 & 0.967 & 0.432 & 0.028 & 0.422 \\
\hline $\begin{array}{l}\text { sodium-dependent } \\
\text { noradrenaline transporter }\end{array}$ & 39 & 0.971 & 0.650 & 0.016 & 0.402 \\
\hline $\begin{array}{l}\text { sodium-dependent serotonin } \\
\text { transporter }\end{array}$ & 35 & 0.962 & 0.594 & 0.026 & 0.410 \\
\hline translocator protein & 12 & 0.992 & 0.705 & 0.031 & 0.558 \\
\hline tubulin & 11 & 0.998 & 0.434 & 0.059 & 0.554 \\
\hline $\begin{array}{l}\text { voltage-dependent L-type } \\
\text { calcium channel }\end{array}$ & 11 & 0.992 & 0.664 & 0.045 & 0.581 \\
\hline $\begin{array}{l}\text { voltage-dependent T-type } \\
\text { calcium channel }\end{array}$ & 14 & 0.987 & 0.344 & 0.064 & 0.356 \\
\hline $\begin{array}{l}\text { voltage-dependent calcium } \\
\text { channel }\end{array}$ & 15 & 0.940 & 0.493 & 0.027 & 0.493 \\
\hline $16 \mathrm{~S}$ rRNA & 15 & 0.999 & 0.632 & 0.042 & 0.589 \\
\hline $\begin{array}{l}\text { 5-hydroxytryptamine } 1 \mathrm{~A} \\
\text { receptor }\end{array}$ & 37 & 0.969 & 0.560 & 0.026 & 0.406 \\
\hline $\begin{array}{l}\text { 5-hydroxytryptamine } 1 \mathrm{~B} \\
\text { receptor }\end{array}$ & 25 & 0.992 & 0.483 & 0.031 & 0.467 \\
\hline $\begin{array}{l}\text { 5-hydroxytryptamine } 1 \mathrm{D} \\
\text { receptor }\end{array}$ & 24 & 0.994 & 0.545 & 0.035 & 0.495 \\
\hline $\begin{array}{l}\text { 5-hydroxytryptamine } 2 \mathrm{~A} \\
\text { receptor }\end{array}$ & 57 & 0.949 & 0.640 & 0.013 & 0.411 \\
\hline $\begin{array}{l}\text { 5-hydroxytryptamine } 2 \mathrm{~B} \\
\text { receptor }\end{array}$ & 15 & 0.984 & 0.248 & 0.038 & 0.441 \\
\hline $\begin{array}{l}\text { 5-hydroxytryptamine } 2 \mathrm{C} \\
\text { receptor }\end{array}$ & 32 & 0.981 & 0.512 & 0.023 & 0.413 \\
\hline $\begin{array}{l}\text { 5-hydroxytryptamine } 3 \\
\text { receptor }\end{array}$ & 17 & 0.983 & 0.293 & 0.044 & 0.379 \\
\hline 5-hydroxytryptamine 7 & 11 & 0.997 & 0.216 & 0.055 & 0.478 \\
\hline
\end{tabular}

${ }^{a}$ For each studied target, the number of active molecules $(n)$, the AUC values, and the results of the 10-fold cross-validation (mean and standard deviation of MPV) are listed. To quantify the chemical diversity of the molecules registered to a given target, the average Tanimoto similarity (Tanimoto diversity, see Methods) was calculated for each target group.

382 produce the further investigated mean MPVs for each target. 383 Table 1 and Figure 4 display the mean MPVs with standard 384 deviation for the 77 targets. This value is used to counter overfitting, which is a known phenomena of multidimensional 385 statistical techniques, and shows whether the classification 386 functions could capture relevant features for the studied targets. 387 


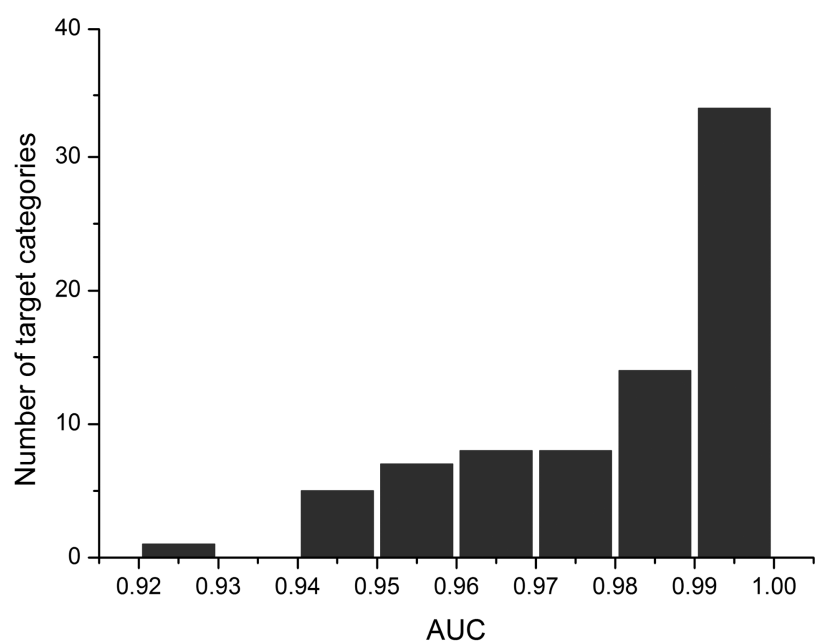

Figure 3. Distribution of AUC values for the studied 77 target groups. ROC analyses were performed to describe classification accuracy. All of the calculated AUC values were greater than 0.92, indicating that a near perfect classification was obtained for the studied targets.

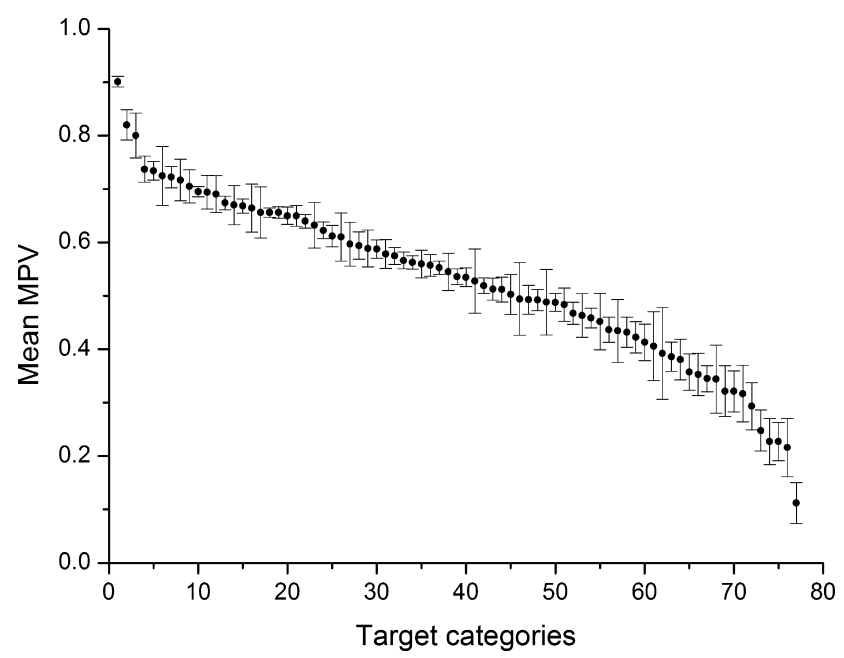

Figure 4. Means of mean probability values (mean MPVs) with standard deviations obtained from 10-fold cross-validation. Mean MPVs calculated from 10-fold cross-validation were used to assess to robustness of the predictive models. The higher an obtained mean MPV, the greater the resistance of the system to the information removal.

388 According to our former analyses, ${ }^{24}$ we consider groups having 389 mean MPV > 0.5 reliably predictable, since it indicates that 390 DPM can classify the majority of the registered molecules into 391 the respective target class. In this work, 45 of the studied 77 392 categories met this criterion, including important pharmaceut393 ical targets such as angiotensin-converting enzyme and carbonic 394 anhydrases, whose inhibitors are widely used antihypertensive 395 agents and diuretics. $\mathrm{D}(2)$ dopamine receptor and histamine $396 \mathrm{H} 1$ receptor also exceeded the threshold, their antagonists are 397 known as antipsychotics and antiallergic agents. High mean $398 \mathrm{MPV}$ is obtained for prostaglandin G/H synthase 1 and 2 399 (often referred to as cyclooxygenase 1 and 2, mean MPVs of 4000.612 and 0.649 ), key enzymes in the mechanism of action of 401 nonsteroidal anti-inflammatory agents. Thirty-one target groups 402 possess medium mean MPV $(0.2<$ mean MPV $<0.5)$ such as 403 acetylcholinesterase or reverse transcriptase (mean MPV of 4040.322 and 0.392 , respectively). These categories are not entirely cohesive based on their IPs, and the redistribution of molecules 405 might improve the reliability of predictions. Only one target, 406 arachidonate 5-lipoxygenase, produced low mean MPV (mean 407 MPV < 0.2), indicating that DPM fails to recognize the 408 originally registered molecules of this target group in external 409 data. Remarkably, this worst obtained mean MPV of 0.112 is 410 considerably higher than the lowest value for effect prediction 411 (0.0028 for antioxidant). ${ }^{23}$ This is in agreement with our 412 expectations that the use of targets improves the prediction 413 power of DPM compared to the more diverse medical effect 414 categories.

Target Selectivity Analysis. On the basis of the validation 416 results, 45 targets were selected for further analysis on the 417 previously defined drug set comprising of 1157 FDA-approved 418 drugs. The predicted off-target profiles of the investigated drugs 419 for these targets were sorted by descending probability and 420 were plotted to produce a so-called target selectivity plot for 421 each drug. Figure 5 displays typical selectivity plots for four 422 drug molecules. In the case of the antiasthmatic agent 423 cinalukast, no targets were predicted among the applied target 424 set therefore its selectivity plot consists of only low probability 425 values. For the antihypertensive agent benazepril, its well- 426 known target the angiotensin-converting enzyme was assigned 427 with a probability of 1.00 . The second highest target probability 428 value is only 0.29 therefore benazepril is a good example of a 429 selective drug concerning our studied targets. Olanzapine, a 430 second generation antipsychotic shows a nonselective predicted 431 target profile with high probability for several targets, mainly 432 dopamine, serotonin, and muscarinic receptor subtypes in 433 agreement with the literature. It is a well-known issue that in 434 case of CNS drugs, the selectively nonselective (sic) drugs offer 435 higher efficacy than the single-target acting drugs. ${ }^{29}$ Thus, their 436 polypharmacology, i.e. affecting multiple targets rather than 437 acting on one single target is essential for a therapeutic effect. 438 For the antiparkinson drug apomorphine, several targets were 439 predicted with high and medium probability, among them 440 unknown interactions can also be found that need further 441 investigation in order to be proved.

Predicted Drug-Target Interactions. Investigating the 443 subset of the selected 45 targets in the binary target profile 444 matrix revealed that 1435 drug-target interactions were 445 originally registered in DrugBank for this data (value of 1). 446 Comparison with the target probability matrix resulted in $79 \% 447$ precision as DPM could correctly predict ( $>0.8$ probability 448 value) 1138 drug-target interactions of them. Applying this 449 probability threshold for the unregistered compounds (value of 450 0 in the target profile matrix), 1074 new drug-target 451 interactions were predicted. These predictions can originate 452 from classification errors; however, considering the known 453 incompleteness of bioactivity databases, part of the predictions 454 may be correct.

Predicted Interactions of Antipsychotics. We examined 456 some of the top drug-target predictions among the 1074457 suggested interactions, and this review revealed that several 458 predictions can be proved by the literature. We focused our 459 investigation on the predicted interactions of antipsychotic 460 molecules. According to our medical effect database presented 461 in our former study, ${ }^{23}$ the studied drug set contains 45 known 462 antipsychotics for which all of the predicted targets above 0.8463 probability threshold were collected. The resulting list 464 comprises of 21 antipsychotics for which 84 drug-target 465 interactions were suggested that were not documented in the 466 DrugBank database. An extensive literature survey revealed that 467 

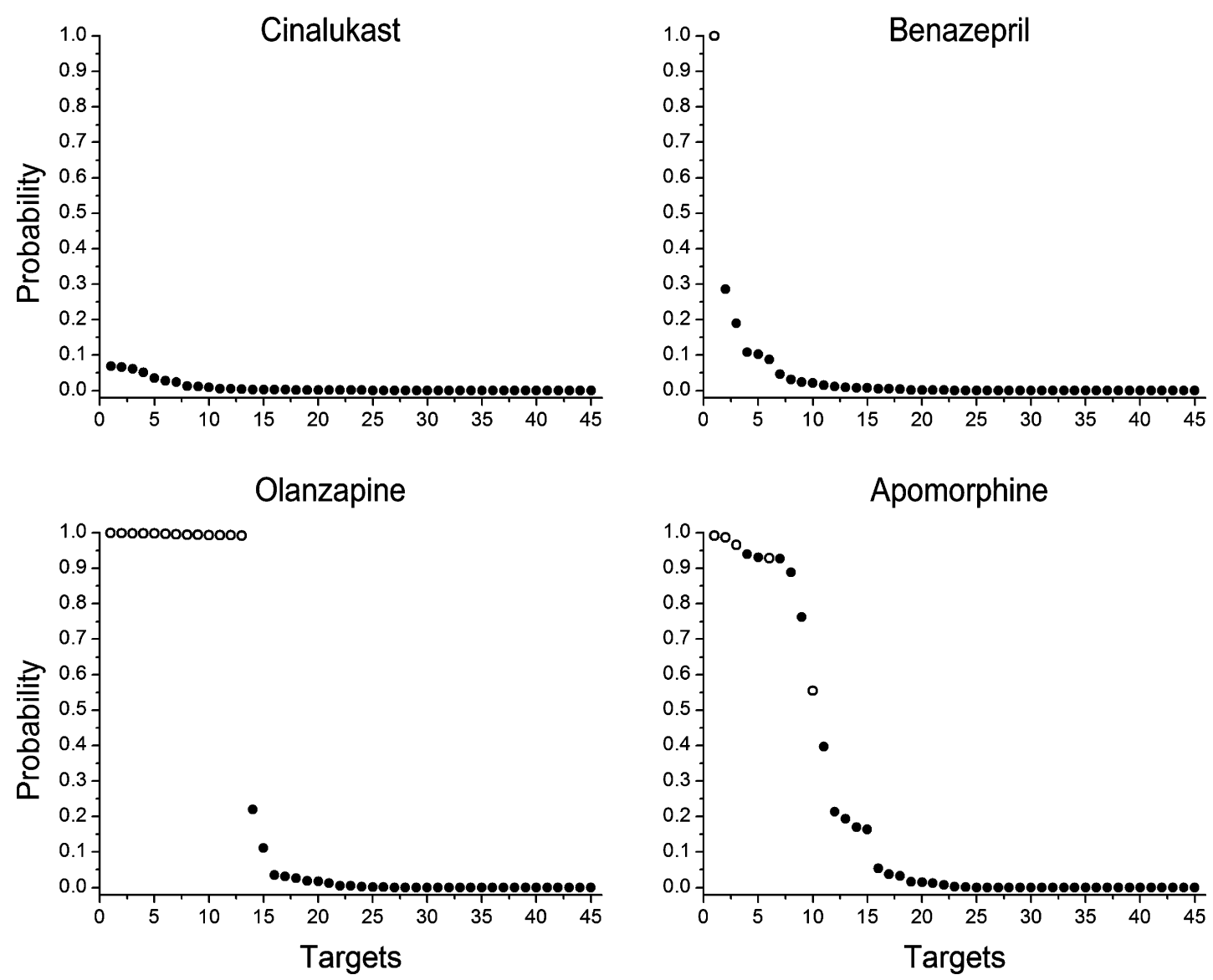

Figure 5. Examples of the selectivity plots. In a selectivity plot, predicted probability values are plotted as a function of the particular targets which are ordered by descending probability values. Hollow circles mark those targets that were already assigned to the studied molecule.

46838 of the suggested interactions are already reported. Results of 469 the survey are summarized in Table 2 for each antipsychotic. 470 For six molecules, no drug-target interactions could be 471 confirmed; however for the remaining drugs, potentially 472 valuable drug-target interactions were predicted.

473 Fluphenazine is a first generation antipsychotic used for the 474 treatment of schizophrenia and other psychotic disorders. In 475 our prediction it gained high prediction value for alpha 1 476 adrenergic and 5-HT1A and 5-HT2A serotonergic receptors. 477 While investigating the well-known weight gain inducing side 478 effect of first and second generation antipsychotics, the research 479 by Kroeze and co-workers also measured the binding affinity of 480 fluphenazine to alpha adrenergic and serotonergic receptors. ${ }^{30}$ 481 Other publications also confirm an existing receptor-ligand 482 binding both with the use of human ${ }^{31,32}$ and rodent ${ }^{33,34}$ 483 5-HT2A receptors. Also high prediction values were measured for 484 alpha 1 adrenergic, 5-HT1A, 5-HT2A serotonergic, and M1 485 muscarinic acethylcholine receptors in the case of the pheno486 thiazine derivative perphenazine which is structurally very 487 similar to the above-mentioned fluphenazine. Literature search 488 also confirmed an existing receptor binding for the serotonergic 489 and adrenergic receptors. ${ }^{30,32}$

490 Sertindole is a second generation antipsychotic with well491 known dopaminergic and serotonergic effects. Our results show 492 a high prediction value for DRD 1, 5-HT1D, M1, and M2 493 muscarinic receptors. All four predictions were confirmed by the 494 literature search including human and animal samples as well. ${ }^{35-39}$ 495 A high prediction value was gained for different kinds of 496 muscarinic acethylcholine receptors (in some cases all five subtypes, in other cases only a few of the existing subtypes) in 497 the case of several compounds. A literature survey confirmed a 498 positive receptor-ligand interaction in the case of chlorpro- 499 mazine,$^{40-43}$ mesoridazine, ${ }^{40}$ loxapine, ${ }^{40,44}$ and sertindole ${ }^{39}$ but 500 failed to prove direct receptorial interaction for example in the 501 case of prochlorpromazine or triflupromazine although these 502 compounds have well-known adverse effects in clinical practice 503 associated with the cholinergic autonomous nervous system 504 (e.g., dry mouth, constipation, urinary retention, blurred vision, etc.). 505

A high probability of possible interaction with alpha 1 adrenergic 506 and type 1 histaminergic receptors was also predicted several 507 times (as mentioned above and also for prochlorperazine, 508 mesoridazine, thiotixen and triflupromazine, pimozide, and 509 prochlorperazine, respectively). These receptors are also 510 associated with adverse effects typical for the antipsychotic 511 drug class, such as orthostatic hypotension, rhinitis in the case 512 of alpha 1 adrenergic and sedation, and weight gain for $\mathrm{H} 1513$ receptor. And again, as with muscarinic receptors, the literature 514 search confirmed a direct receptor-compound interaction only 515 in some part of the cases (Table 2).

A possible interpretation of the large number of false positive 517 targets can be the incompleteness of the target database. To 518 investigate this issue, a validation study for a small fraction of 519 the false positive interactions was performed by using the 520 ChEMBL database. We could confirm that $10 \%$ of the 521 predicted false positives are in fact true positives according to 522 the ChEMBL database (see the Supporting Information). Thus, 523 ChEMBL provided additional information on drug-target 524 interactions compared to DrugBank but could not validate the 525 
Table 2. Results of the Literature Survey Performed for Antipsychotics ${ }^{a}$

\begin{tabular}{|c|c|c|c|c|}
\hline name & target & predicted probability & result & ref \\
\hline \multirow[t]{6}{*}{ acepromazine } & 5-hydroxytryptamine $2 \mathrm{C}$ receptor & 0.986 & no data & \\
\hline & muscarinic acetylcholine receptor M1 & 0.949 & yes & $b$ \\
\hline & muscarinic acetylcholine receptor M2 & 0.976 & yes & $b$ \\
\hline & muscarinic acetylcholine receptor M3 & 0.839 & no data & \\
\hline & muscarinic acetylcholine receptor M4 & 0.971 & no data & \\
\hline & muscarinic acetylcholine receptor M5 & 0.979 & no data & \\
\hline \multirow[t]{9}{*}{ aceprometazine } & 5-hydroxytryptamine $2 \mathrm{~A}$ receptor & 0.996 & no data & \\
\hline & 5-hydroxytryptamine $2 \mathrm{C}$ receptor & 0.926 & no data & \\
\hline & alpha-1A adrenergic receptor & 0.963 & no data & \\
\hline & $\mathrm{D}(1)$ dopamine receptor & 0.999 & no data & \\
\hline & $\mathrm{D}(2)$ dopamine receptor & 0.997 & no data & \\
\hline & muscarinic acetylcholine receptor $\mathrm{M} 1$ & 0.930 & no data & \\
\hline & muscarinic acetylcholine receptor M2 & 0.958 & no data & \\
\hline & muscarinic acetylcholine receptor M4 & 0.915 & no data & \\
\hline & muscarinic acetylcholine receptor M5 & 0.975 & no data & \\
\hline \multirow[t]{2}{*}{ carphenazine } & 5-hydroxytryptamine $2 \mathrm{~A}$ receptor & 0.949 & no data & \\
\hline & alpha-1A adrenergic receptor & 0.912 & no data & \\
\hline \multirow[t]{4}{*}{ chlorpromazine } & muscarinic acetylcholine receptor M1 & 0.923 & yes & $40,41,43$ \\
\hline & muscarinic acetylcholine receptor M2 & 0.955 & yes & $40-43$ \\
\hline & muscarinic acetylcholine receptor M3 & 0.911 & yes & $30,40,41,43$ \\
\hline & muscarinic acetylcholine receptor M5 & 0.936 & yes & $40,41,43$ \\
\hline \multirow[t]{4}{*}{ chlorprothixene } & 5-hydroxytryptamine $1 \mathrm{~A}$ receptor & 0.962 & no data & \\
\hline & alpha-1A adrenergic receptor & 0.977 & no data & \\
\hline & sodium-dependent noradrenaline transporter & 0.984 & yes & 45 \\
\hline & sodium-dependent serotonin transporter & 0.993 & yes & 45 \\
\hline \multirow[t]{2}{*}{ droperidol } & 5-hydroxytryptamine $1 \mathrm{~A}$ receptor & 0.873 & yes & 46 \\
\hline & 5-hydroxytryptamine $1 \mathrm{D}$ receptor & 0.938 & no data & \\
\hline fencamfamine & sodium-dependent noradrenaline transporter & 0.914 & no data & \\
\hline \multirow[t]{5}{*}{ flupenthixol } & 5-hydroxytryptamine $1 \mathrm{~A}$ receptor & 0.814 & yes & 47 \\
\hline & muscarinic acetylcholine receptor M2 & 0.926 & no data & \\
\hline & muscarinic acetylcholine receptor M3 & 0.855 & no data & \\
\hline & muscarinic acetylcholine receptor M4 & 0.974 & no data & \\
\hline & muscarinic acetylcholine receptor M5 & 0.980 & no data & \\
\hline \multirow[t]{3}{*}{ fluphenazine } & 5-hydroxytryptamine $1 \mathrm{~A}$ receptor & 0.869 & yes & 30,47 \\
\hline & 5-hydroxytryptamine $2 \mathrm{~A}$ receptor & 0.991 & yes & $30,31,33,47,48$ \\
\hline & Alpha-1A adrenergic receptor & 0.936 & yes & $30,32,49$ \\
\hline \multirow[t]{4}{*}{ loxapine } & DNA & 0.856 & no data & \\
\hline & histamine $\mathrm{H} 1$ receptor & 0.925 & yes & $30,32,44,49$ \\
\hline & muscarinic acetylcholine receptor $\mathrm{M} 1$ & 0.942 & yes & 40,44 \\
\hline & muscarinic acetylcholine receptor M4 & 0.865 & yes & 40 \\
\hline \multirow[t]{7}{*}{ mesoridazine } & alpha-1A adrenergic receptor & 0.860 & yes & $32,49,50$ \\
\hline & $\mathrm{D}(1)$ dopamine receptor & 0.996 & yes & 51,52 \\
\hline & muscarinic acetylcholine receptor M1 & 0.900 & yes & 40 \\
\hline & muscarinic acetylcholine receptor M2 & 0.948 & yes & 40 \\
\hline & muscarinic acetylcholine receptor M3 & 0.949 & yes & 40 \\
\hline & muscarinic acetylcholine receptor M4 & 0.943 & yes & 40 \\
\hline & muscarinic acetylcholine receptor M5 & 0.906 & yes & 40 \\
\hline methotrimeprazine & 5-hydroxytryptamine $1 \mathrm{~A}$ receptor & 0.862 & no data & \\
\hline \multirow[t]{4}{*}{ perphenazine } & 5-hydroxytryptamine $1 \mathrm{~A}$ receptor & 0.950 & yes & 30 \\
\hline & 5-hydroxytryptamine $2 \mathrm{~A}$ receptor & 0.982 & yes & 30 \\
\hline & alpha-1A adrenergic receptor & 0.906 & yes & $30,32,49$ \\
\hline & muscarinic acetylcholine receptor M1 & 0.917 & no data & \\
\hline pimozide & histamine $\mathrm{H} 1$ receptor & 0.932 & yes & 30,37 \\
\hline \multirow[t]{8}{*}{ prochlorperazine } & 5-hydroxytryptamine $1 \mathrm{~A}$ receptor & 0.930 & no data & \\
\hline & 5-hydroxytryptamine $2 \mathrm{~A}$ receptor & 0.965 & no data & \\
\hline & 5-hydroxytryptamine $2 \mathrm{C}$ receptor & 0.900 & yes & 33,53 \\
\hline & alpha-1A adrenergic receptor & 0.986 & yes & 32,49 \\
\hline & $\mathrm{D}(1)$ dopamine receptor & 0.976 & no data & \\
\hline & histamine $\mathrm{H} 1$ receptor & 0.905 & yes & 32,49 \\
\hline & muscarinic acetylcholine receptor M1 & 0.944 & no data & \\
\hline & muscarinic acetylcholine receptor M2 & 0.899 & no data & \\
\hline
\end{tabular}


Table 2. continued

\begin{tabular}{|c|c|c|c|c|}
\hline name & target & predicted probability & result & ref \\
\hline \multirow{5}{*}{ propericiazine } & muscarinic acetylcholine receptor $\mathrm{M} 3$ & 0.947 & no data & \\
\hline & muscarinic acetylcholine receptor M5 & 0.860 & no data & \\
\hline & 5-hydroxytryptamine $1 \mathrm{~A}$ receptor & 0.907 & no data & \\
\hline & 5-hydroxytryptamine $2 \mathrm{~A}$ receptor & 0.985 & no data & \\
\hline & $\mathrm{D}(2)$ dopamine receptor & 0.984 & no data & \\
\hline \multirow{3}{*}{ sertindole } & muscarinic acetylcholine receptor $\mathrm{M} 1$ & 0.906 & no data & \\
\hline & 5-hydroxytryptamine $1 \mathrm{D}$ receptor & 0.878 & yes & $30,37,38$ \\
\hline & $\mathrm{D}(1)$ dopamine receptor & 0.875 & yes & 35 \\
\hline \multirow{5}{*}{$\begin{array}{l}\text { thiothixene } \\
\text { trifluperazine }\end{array}$} & muscarinic acetylcholine receptor $\mathrm{M} 1$ & 0.945 & yes & 39 \\
\hline & muscarinic acetylcholine receptor $\mathrm{M} 2$ & 0.826 & yes & 39 \\
\hline & alpha-1A adrenergic receptor & 0.851 & yes & 30 \\
\hline & 5-hydroxytryptamine 1A receptor & 0.908 & yes & 30,54 \\
\hline & 5-hydroxytryptamine $2 \mathrm{~A}$ receptor & 0.995 & yes & $30,31,48,54-56$ \\
\hline \multirow{5}{*}{ triflupromazine } & $\mathrm{D}(1)$ dopamine receptor & 1.000 & yes & 57,58 \\
\hline & 5-hydroxytryptamine $1 \mathrm{~A}$ receptor & 0.872 & no data & \\
\hline & 5-hydroxytryptamine $2 \mathrm{~A}$ receptor & 0.987 & no data & \\
\hline & alpha-1A adrenergic receptor & 0.962 & no data & \\
\hline & histamine $\mathrm{H} 1$ receptor & 0.976 & yes & 59 \\
\hline \multirow{5}{*}{ zuclopenthixol } & muscarinic acetylcholine receptor M4 & 0.831 & no data & \\
\hline & muscarinic acetylcholine receptor M5 & 0.935 & no data & \\
\hline & 5-hydroxytryptamine $1 \mathrm{~A}$ receptor & 0.894 & no data & \\
\hline & 5-hydroxytryptamine $2 \mathrm{C}$ receptor & 0.914 & no data & \\
\hline & muscarinic acetylcholine receptor $\mathrm{M} 1$ & 0.808 & no data & \\
\hline
\end{tabular}

${ }^{a}$ For each studied antipsychotic, the predicted drug-target interactions (probability $>0.8$ ) are displayed. An extensive literature survey revealed

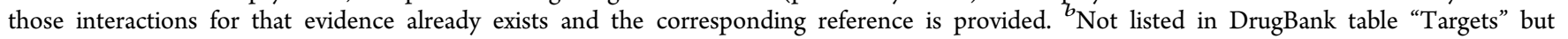
mentioned in the "Pharmacology" section.

526 false positive interactions so widely. The reason might be that 527 targets which are important in the clinical effect are in the focus 528 of the majority of the databases and receptors which mediate 529 adverse effects are not so well documented. Another inter530 pretation can be that these, usually general and not easily 531 quantifiable side effects such as dry mouth and constipation for 532 example, are traditionally considered as anticholinergic, but in 533 some cases, these might be at least partially mediated by other 534 transmitter systems as well in line with the model of 535 polypharmacology.

536 Those predictions for which no literature evidence exists 537 might be demonstrated experimentally since it is also possible 538 that a given drug was not tested against the predicted off539 targets. On the basis of our previous DPM analysis using 540 medical effects instead of targets, we already obtained valuable 541 predictions which were validated by in vitro experiments with a 542 high hit rate of $47-84 \%$ (unpublished results).

\section{$543 \square$ CONCLUSIONS}

544 In this paper, the applicability of DPM for in silico target fishing 545 was investigated using 77 target classes, each containing at least 54610 active molecules. High classification accuracies were 547 obtained in all cases. The robustness of the prediction results 548 was checked by 10 -fold cross-validation which revealed those 549 targets for that the performance of DPM is highly reliable. 550 These 45 categories were used in a subsequent analysis which 551 aimed at predicting the off-target profiles (limited to the 552 studied categories) of currently approved FDA drugs. $79 \%$ of 553 the known drug-target interactions in this data set were 554 correctly predicted by DPM. Additionally 1074 new drug555 target interactions were suggested. A pilot study was presented 556 that aimed at confirming part of the suggested drug-target 557 interactions for antipsychotic molecules by a literature survey.
$45 \%$ of the 84 suggested interactions were demonstrated and 558 references were provided.

Our study supports the theory of polypharmacology by 560 pointing out that drugs usually act on several targets and have a 561 characteristic off-target profile that contains valuable informa- 562 tion for future drug development. DPM is able to find 563 previously unknown pharmaceutical targets of the studied 564 compounds; therefore, the method may serve as a good starting 565 point for drug repositioning that aims at finding new medical 566 applications of well-known drug molecules.

\section{ASSOCIATED CONTENT}

568

Supporting Information

569

Detailed description of IP generation, example calculation on a 570 small dataset that illustrates the different steps of the DPM 571 method, validation of the predicted drug-target interactions by 572 ChEMBL data, and Table S1: list of the names and the Protein 573 Data Bank entries of the 135 proteins used. This material is 574 available free of charge via the Internet at http://pubs.acs.org. 575

\section{AUTHOR INFORMATION 576}

Corresponding Author

577

*Phone: +36 13722500 ext. 8780. Fax: +36 1381 2172. E- 578 mail: malna@elte.hu. $\quad 579$

Notes

The authors declare no competing financial interest.

\section{ACKNOWLEDGMENTS}

This work was funded by the Hungarian Academy of Sciences, 583 HAS-ELTE research group ID: 01055. The European Research 584 Council has provided financial support under the European 585 Community's Seventh Framework Programme (FP7/2007- 586 2013)/ERC grant agreement no. [208319]. This work was 587 
588 supported by the European Union and cofinanced by the 589 European Regional Development Fund (New Széchenyi Plan 590 KMOP-1.1.1-09/1-2009-0045).

\section{ABBREVIATIONS}

592 AUC, area under the curve; CCA, canonical correlation 593 analysis; DPM, drug profile matching; TP, target profile; 594 FDA, Food and Drug Administration; FPR, false positive rate; 595 IP, interaction pattern; LDA, linear discriminant analysis; PDB, 596 Protein Data Bank; ROC, receiver operating characteristic; $597 \mathrm{TPR}$, true positive rate

\section{$598 \square$ REFERENCES}

599 (1) Nettles, J. H.; Jenkins, J. L.; Bender, A.; Deng, Z.; Davies, J. W.; 600 Glick, M. Bridging chemical and biological space: "target fishing" using 601 2D and 3D molecular descriptors. J. Med. Chem. 2006, 49, 6802-6810. 602 (2) Hopkins, A. L. Network pharmacology: the next paradigm in 603 drug discovery. Nat. Chem. Biol. 2008, 4, 682-690.

604 (3) Metz, J. T.; H., P. Rational approaches to targeted 605 polypharmacology: creating and navigating protein-ligand interaction 606 networks. Curr. Opin. Chem. Biol. 2010, 14, 498-504.

607 (4) Koutsoukas, A.; Simms, B.; Kirchmair, J.; Bond, P. J.; Whitmore, 608 A. V.; Zimmer, S.; Young, M. P.; Jenkins, J. L.; Glick, M.; Glen, R. C.; 609 Bender, A. From in silico target prediction to multi-target drug design: 610 current databases, methods and applications. J. Proteom. 2011, 74, $6112554-2574$.

612 (5) Sheridan, R. P.; Kearsley, S. K. Why do we need so many 613 chemical similarity search methods? Drug Discov. Today 2002, 7, 903614911.

615 (6) Salim, N.; Holliday, J.; Willett, P. Combination of fingerprint616 based similarity coefficients using data fusion. J. Chem. Inf. Comput. Sci. 617 2003, 43, 435-442.

618 (7) AbdulHameed, M. D.; Chaudhury, S.; Singh, N.; Sun, H.; 619 Wallqvist, A.; Tawa, G. J. Exploring polypharmacology using a ROCS620 based target fishing approach. J. Chem. Inf. Model. 2012, 52, 492-505. 621 (8) Poroikov, V.; Filimonov, D.; Lagunin, A.; Gloriozova, T.; 622 Zakharov, A. PASS: identification of probable targets and mechanisms 623 of toxicity. SAR QSAR Environ. Res. 2007, 18, 101-110.

624 (9) Nigsch, F.; Bender, A.; Jenkins, J. L.; Mitchell, J. B. Ligand-target 625 prediction using Winnow and naive Bayesian algorithms and the 626 implications of overall performance statistics. J. Chem. Inf. Model. 2008, $62748,2313-2325$.

628 (10) Keiser, M. J.; Roth, B. L.; Armbruster, B. N.; Ernsberger, P.; 629 Irwin, J. J.; Shoichet, B. K. Relating protein pharmacology by ligand 630 chemistry. Nat. Biotechnol. 2007, 25, 197-206.

631 (11) Keiser, M. J.; Setola, V.; Irwin, J. J.; Laggner, C.; Abbas, A. I.; 632 Hufeisen, S. J.; Jensen, N. H.; Kuijer, M. B.; Matos, R. C.; Tran, T. B.; 633 Whaley, R.; Glennon, R. A.; Hert, J.; Thomas, K. L.; Edwards, D. D.; 634 Shoichet, B. K.; Roth, B. L. Predicting new molecular targets for 635 known drugs. Nature 2009, 462, 175-181.

636 (12) Liu, X.; Ouyang, S.; Yu, B.; Liu, Y.; Huang, K.; Gong, J.; Zheng, 637 S.; Li, Z.; Li, H.; Jiang, H. PharmMapper server: a web server for 638 potential drug target identification using pharmacophore mapping 639 approach. Nucleic Acids Res. 2010, 38, W609-614.

640 (13) Chen, X.; Ung, C. Y.; Chen, Y. Can an in silico drug-target 641 search method be used to probe potential mechanisms of medicinal 642 plant ingredients? Nat. Prod. Rep. 2003, 20, 432-444.

643 (14) Li, H.; Gao, Z.; Kang, L.; Zhang, H.; Yang, K.; Yu, K.; Luo, X.; 644 Zhu, W.; Chen, K.; Shen, J.; Wang, X.; Jiang, H. TarFisDock: a web 645 server for identifying drug targets with docking approach. Nucleic Acids 646 Res. 2006, 34, W219-224.

647 (15) Briem, H.; Kuntz, I. D. Molecular similarity based on DOCK648 generated fingerprints. J. Med. Chem. 1996, 39, 3401-3408.

649 (16) Lessel, U. F.; Briem, H. Flexsim-X: a method for the detection 650 of molecules with similar biological activity. J. Chem. Inf. Comput. Sci. $6512000,40,246-253$.
(17) Fukunishi, Y.; Hojo, S.; Nakamura, H. An efficient in silico 652 screening method based on the protein-compound affinity matrix and 653 its application to the design of a focused library for cytochrome P450 654 (CYP) ligands. J. Chem. Inf. Model. 2006, 46, 2610-2622. 655

(18) Kauvar, L. M.; Higgins, D. L.; Villar, H. O.; Sportsman, J. R; 656 Engqvist-Goldstein, A.; Bukar, R.; Bauer, K. E.; Dilley, H.; Rocke, D. 657 M. Predicting ligand binding to proteins by affinity fingerprinting. 658 Chem. Biol. 1995, 2, 107-118.

(19) Kauvar, L. M.; Villar, H. O.; Sportsman, J. R.; Higgins, D. L.; 660 Schmidt, D. E., Jr. Protein affinity map of chemical space. J. 661 Chromatogr. B Biomed. Sci. Appl. 1998, 715, 93-102. 662

(20) Bender, A.; Jenkins, J. L.; Glick, M.; Deng, Z.; Nettles, J. H.; 663 Davies, J. W. "Bayes affinity fingerprints" improve retrieval rates in 664 virtual screening and define orthogonal bioactivity space: when are 665 multitarget drugs a feasible concept? J. Chem. Inf. Model. 2006, 46, 666 2445-2456.

667

(21) Briem, H.; Lessel, U. F. In vitro and in silico affinity fingerprints: 668 Finding similarities beyond structural classes. Perspect. Drug Discovery 669 Des. 2000, 20, 231-244.

670

(22) Fukunishi, Y.; Mikami, Y.; Takedomi, K.; Yamanouchi, M.; 671 Shima, H.; Nakamura, H. Classification of chemical compounds by 672 protein-compound docking for use in designing a focused library. J. 673 Med. Chem. 2006, 49, 523-533.

674

(23) Simon, Z.; Peragovics, A.; Vigh-Smeller, M.; Csukly, G.; 675 Tombor, L.; Yang, Z.; Zahoranszky-Kohalmi, G.; Vegner, L.; Jelinek, 676 B.; Hari, P.; Hetenyi, C.; Bitter, I.; Czobor, P.; Malnasi-Csizmadia, A. 677 Drug effect prediction by polypharmacology-based interaction 678 profiling. J. Chem. Inf. Model. 2012, 52, 134-145.

679

(24) Peragovics, A.; Simon, Z.; Brandhuber, I.; Jelinek, B.; Hari, P.; 680 Hetenyi, C.; Czobor, P.; Malnasi-Csizmadia, A. Contribution of 2D 681 and 3D Structural Features of Drug Molecules in the Prediction of 682 Drug Profile Matching. J. Chem. Inf. Model. 2012, 52, 1733-1744. 683

(25) Jiang, X.; Kumar, K.; Hu, X.; Wallqvist, A.; Reifman, J. DOVIS 684 2.0: an efficient and easy to use parallel virtual screening tool based on 685 AutoDock 4.0. Chem. Cent. J. 2008, 2, 18.

(26) Huey, R.; Morris, G. M.; Olson, A. J.; Goodsell, D. S. A 687 semiempirical free energy force field with charge-based desolvation. J. 688 Comput. Chem. 2007, 28, 1145-1152.

689

(27) Wang, R.; Lai, L.; Wang, S. Further development and validation 690 of empirical scoring functions for structure-based binding affinity 691 prediction. J. Comput. Aided. Mol. Des. 2002, 16, 11-26.

692

(28) Truchon, J. F.; Bayly, C. I. Evaluating virtual screening methods: 693 good and bad metrics for the "early recognition" problem. J. Chem. Inf. 694 Model. 2007, 47, 488-508.

695

(29) Roth, B. L.; Sheffler, D. J.; Kroeze, W. K. Magic shotguns versus 696 magic bullets: selectively non-selective drugs for mood disorders and 697 schizophrenia. Nat. Rev. Drug Discov. 2004, 3, 353-359. 698

(30) Kroeze, W. K.; Hufeisen, S. J.; Popadak, B. A.; Renock, S. M.; 699 Steinberg, S.; Ernsberger, P.; Jayathilake, K.; Meltzer, H. Y.; Roth, B. L. 700 H1-histamine receptor affinity predicts short-term weight gain for 701 typical and atypical antipsychotic drugs. Neuropsychopharmacology 702 2003, 28, 519-526.

(31) Seeman, P.; Tallerico, T. Antipsychotic drugs which elicit little 704 or no parkinsonism bind more loosely than dopamine to brain D2 705 receptors, yet occupy high levels of these receptors. Mol. Psychiatry 706 1998, 3, 123-134.

(32) Richelson, E.; Nelson, A. Antagonism by neuroleptics of 708 neurotransmitter receptors of normal human brain in vitro. Eur. J. 709 Pharmacol. 1984, 103, 197-204.

710

(33) Roth, B. L.; Ciaranello, R. D.; Meltzer, H. Y. Binding of typical 711 and atypical antipsychotic agents to transiently expressed 5-HT1C 712 receptors. J. Pharmacol. Exp. Ther. 1992, 260, 1361-1365.

713

(34) Canton, H.; Verriele, L.; Millan, M. J. Competitive antagonism 714 of serotonin (5-HT)2C and 5-HT2A receptor-mediated phosphoinosi- 715 tide (PI) turnover by clozapine in the rat: a comparison to other 716 antipsychotics. Neurosci. Lett. 1994, 181, 65-68.

717

(35) Arnt, J.; Skarsfeldt, T. Do novel antipsychotics have similar 718 pharmacological characteristics? A review of the evidence. Neuro- 719 psychopharmacology 1998, 18, 63-101.
720 
721 (36) Balle, T.; Perregaard, J.; Ramirez, M. T.; Larsen, A. K.; Soby, K. 722 K.; Liljefors, T.; Andersen, K. Synthesis and structure-affinity 723 relationship investigations of 5-heteroaryl-substituted analogues of 724 the antipsychotic sertindole. A new class of highly selective alpha(1) 725 adrenoceptor antagonists. J. Med. Chem. 2003, 46, 265-283.

726 (37) Richelson, E.; Souder, T. Binding of antipsychotic drugs to 727 human brain receptors focus on newer generation compounds. Life Sci. 728 2000, 68, 29-39.

(38) Schotte, A.; Janssen, P. F.; Gommeren, W.; Luyten, W. H.; Van 730 Gompel, P.; Lesage, A. S.; De Loore, K.; Leysen, J. E. Risperidone 731 compared with new and reference antipsychotic drugs: in vitro and in 732 vivo receptor binding. Psychopharmacology (Berl) 1996, 124, 57-73.

733 (39) Wermuth, C. G. Selective optimization of side activities: another 734 way for drug discovery. J. Med. Chem. 2004, 47, 1303-1314.

735 (40) Bolden, C.; Cusack, B.; Richelson, E. Antagonism by 736 antimuscarinic and neuroleptic compounds at the five cloned human 737 muscarinic cholinergic receptors expressed in Chinese hamster ovary 738 cells. J. Pharmacol. Exp. Ther. 1992, 260, 576-580.

739 (41) Bymaster, F. P.; Felder, C. C.; Tzavara, E.; Nomikos, G. G.; 740 Calligaro, D. O.; McKinzie, D. L. Muscarinic mechanisms of 741 antipsychotic atypicality. Prog. Neuropsychopharmacol. Biol. Psychiatry 742 2003, 27, 1125-1143.

743 (42) Kovacs, I.; Yamamura, H. I.; Waite, S. L.; Varga, E. V.; Roeske, 744 W. R. Pharmacological comparison of the cloned human and rat M2 745 muscarinic receptor genes expressed in the murine fibroblast (B82) 746 cell line. J. Pharmacol. Exp. Ther. 1998, 284, 500-507.

747 (43) Liegeois, J. F.; Bruhwyler, J.; Damas, J.; Nguyen, T. P.; Chleide, 748 E. M.; Mercier, M. G.; Rogister, F. A.; Delarge, J. E. New 749 pyridobenzodiazepine derivatives as potential antipsychotics: synthesis 750 and neurochemical study. J. Med. Chem. 1993, 36, 2107-2114.

751 (44) Liao, Y.; Venhuis, B. J.; Rodenhuis, N.; Timmerman, W.; 752 Wikstrom, H.; Meier, E.; Bartoszyk, G. D.; Bottcher, H.; Seyfried, C. 753 A.; Sundell, S. New (sulfonyloxy)piperazinyldibenzazepines as 754 potential atypical antipsychotics: chemistry and pharmacological 755 evaluation. J. Med. Chem. 1999, 42, 2235-2244.

756 (45) Tatsumi, M.; Jansen, K.; Blakely, R. D.; Richelson, E. 757 Pharmacological profile of neuroleptics at human monoamine 758 transporters. Eur. J. Pharmacol. 1999, 368, 277-283.

759 (46) Gentil, B.; Macquin-Mavier, I.; Lienhart, A.; Harf, A. Droperidol 760 prevents serotonin-induced bronchospasm in the guinea pig. Anesth 761 Analg. 1991, 72, 612-615.

762 (47) Toll, L.; Berzetei-Gurske, I. P.; Polgar, W. E.; Brandt, S. R.; 763 Adapa, I. D.; Rodriguez, L.; Schwartz, R. W.; Haggart, D.; O’Brien, A.; 764 White, A.; Kennedy, J. M.; Craymer, K.; Farrington, L.; Auh, J. S. 765 Standard binding and functional assays related to medications 766 development division testing for potential cocaine and opiate narcotic 767 treatment medications. NIDA Res Monogr. 1998, 178, 440-466.

768 (48) Roth, B. L.; Tandra, S.; Burgess, L. H.; Sibley, D. R.; Meltzer, H. 769 Y. D4 dopamine receptor binding affinity does not distinguish between 770 typical and atypical antipsychotic drugs. Psychopharmacology (Berl) 771 1995, 120, 365-368.

772 (49) Richelson, E. Neuroleptic binding to human brain receptors: 773 relation to clinical effects. Ann. N.Y. Acad. Sci. 1988, 537, 435-442.

774 (50) Bylund, D. B. Interactions of neuroleptic metabolites with 775 dopaminergic, alpha adrenergic and muscarinic cholinergic receptors. J. 776 Pharmacol. Exp. Ther. 1981, 217, 81-86.

777 (51) Black, J. L.; Richelson, E. Antipsychotic drugs: prediction of 778 side-effect profiles based on neuroreceptor data derived from human 779 brain tissue. Mayo Clin. Proc. 1987, 62, 369-372.

780 (52) Poling, A.; Cleary, J.; Berens, K.; Thompson, T. Neuroleptics 781 and learning: effects of haloperidol, molindone, mesoridazine and 782 thioridazine on the behavior of pigeons under a repeated acquisition 783 procedure. J. Pharmacol. Exp. Ther. 1990, 255, 1240-1245.

784 (53) Herrick-Davis, K.; Grinde, E.; Teitler, M. Inverse agonist activity 785 of atypical antipsychotic drugs at human 5-hydroxytryptamine2C 786 receptors. J. Pharmacol. Exp. Ther. 2000, 295, 226-232.

787 (54) Scott, M. K.; Martin, G. E.; DiStefano, D. L.; Fedde, C. L.; 788 Kukla, M. J.; Barrett, D. L.; Baldy, W. J.; Elgin, R. J., Jr.; Kesslick, J. M.;
Mathiasen, J. R.; et al. Pyrrole mannich bases as potential antipsychotic 789 agents. J. Med. Chem. 1992, 35, 552-558. 790 (55) Seeman, P.; Corbett, R.; Van Tol, H. H. Atypical neuroleptics 791 have low affinity for dopamine D2 receptors or are selective for D4 792 receptors. Neuropsychopharmacology 1997, 16, 93-110 discussion 793 $111-135$.

794

(56) Yevich, J. P.; New, J. S.; Smith, D. W.; Lobeck, W. G.; Catt, J. 795 D.; Minielli, J. L.; Eison, M. S.; Taylor, D. P.; Riblet, L. A.; Temple, D. 796 L., Jr. Synthesis and biological evaluation of 1-(1,2-benzisothiazol-3- 797 yl)- and (1,2-benzisoxazol-3-yl)piperazine derivatives as potential 798 antipsychotic agents. J. Med. Chem. 1986, 29, 359-369. 799

(57) Creese, I.; Burt, D. R.; Snyder, S. H. Dopamine receptor binding 800 predicts clinical and pharmacological potencies of antischizophrenic 801 drugs. J. Neuropsychiatry Clin. Neurosci. 1996, 8, 223-226.

802

(58) Burt, D. R.; Creese, I.; Snyder, S. H. Properties of 803 $[3 \mathrm{H}]$ haloperidol and $[3 \mathrm{H}]$ dopamine binding associated with dop- 804 amine receptors in calf brain membranes. Mol. Pharmacol. 1976, 12, 805 $800-812$.

806

(59) Tran, V. T.; Chang, R. S.; Snyder, S. H. Histamine H1 receptors 807 identified in mammalian brain membranes with $[3 \mathrm{H}]$ mepyramine. 808 Proc. Natl. Acad. Sci. USA 1978, 75, 6290-6294.

\section{9}

